\title{
An observational study of type, timing, and severity of childhood maltreatment and preterm birth
}

\author{
Sabrina C Selk, ${ }^{1}$ Janet W Rich-Edwards, ${ }^{2,3}{ }^{3}$ arestan Koenen, ${ }^{4}$ Laura D Kubzansky ${ }^{1}$
}

${ }^{1}$ Department of Social and Behavioral Sciences, Harvard School of Public Health, Boston, Massachusetts, USA ${ }^{2}$ Channing Division of Network Medicine, Department of Medicine, Connors Center for Women's Health and Gender Biology, Brigham and Women's Hospital and Harvard Medical School, Boston, Massachusetts, USA

${ }^{3}$ Department of Epidemiology, Harvard School of Public Health, Boston, Massachusetts, USA

${ }^{4}$ Department of Epidemiology, Columbia Mailman School of Public Health, Boston, Massachusetts, USA

\section{Correspondence to} Dr Sabrina Selk, 30 Winter Street, 6th Floor, Boston, MA 02108,USA; sselk@nichq.org

Received 1 July 2015

Revised 1 November 2015 Accepted 20 November 2015

Published Online First

8 March 2016

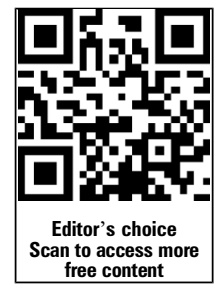

CrossMark

To cite: Selk SC, RichEdwards JW, Koenen K, et al. J Epidemiol Community Health 2016;70:589-595.

\section{ABSTRACT}

Background Childhood maltreatment has been linked to preterm birth ( $<37$ weeks gestation) in some studies, but these findings have been inconsistent, and it remains unclear whether type, timing or severity of maltreatment are associated with risk of preterm birth. The aim of this observational study was to explore type of maltreatment (child and adolescent physical and sexual abuse and harsh parenting) as risk factors for preterm birth.

Methods We examined these associations in a crosssectional analysis of the Nurses' Health Study II cohort of female nurses. Women completed a questionnaire about experiences of sexual abuse, physical abuse or harsh parenting, along with pregnancy outcomes. Logistic regression models adjusted for relevant covariates including age, race, alcohol and cigarette use during pregnancy, age at menarche, marital status, adult income, body mass index $\left(\mathrm{kg} / \mathrm{m}^{2}\right)$ at age 18 , physical abuse in pregnancy, and childhood socioeconomic position.

Results Among 51434 first births, 4110 were preterm ( $8 \%$ of births). Forced sexual activity in childhood or adolescence was associated with a $22 \%$ increased odds of preterm birth ( $\mathrm{OR}=1.22,95 \% \mathrm{Cl} 1.10$ to 1.35$)$. Maltreatment involving sexual touch, physical abuse or harsh parenting was not associated with preterm birth in this sample.

Conclusions Women who experience forced sexual activity in childhood or adolescence may have an increased likelihood of delivering preterm in adulthood.

\section{INTRODUCTION}

Preterm birth (PTB) is a leading cause of infant morbidity and mortality with a higher incidence in the USA (12-13\%) compared with other developed nations $(5-9 \%){ }^{1}$ Literature reviews support maternal stress exposure, including violence, as a risk factor for PTB. ${ }^{2}{ }^{3}$ PTB is hypothesised to act like a chronic disease, where activation of neuroendocrine responses from psychosocial stress causing physiological 'wear and tear' across the life course. In particular, child and adolescent maltreatment may be a potential risk factor for PTB. ${ }^{4-12}$ Findings to date are contradictory, possibly reflecting the inconsistencies in measurement of maltreatment, with variations in type, timing, frequency and severity of maltreatment reported. To date, no large studies have simultaneously considered all of these factors. This paper examines early life exposure to maltreatment across these dimensions and adulthood risk of PTB.

Maltreatment in childhood is common. In a given year, one in seven children will experience some form of maltreatment, ${ }^{13}$ including physical, sexual, emotional abuse or neglect. Growing evidence also links exposure to childhood abuse with negative behaviours and problems in adulthood including drug and alcohol use, ${ }^{14-16}$ obesity, ${ }^{17}$ mental health problems, ${ }^{18}{ }^{19}$ sexual risk taking, ${ }^{20} 21$ and revictimisation, ${ }^{22} 23$ along with health conditions such as hypertension, and diabetes, ${ }^{24-27}$ which may increase risk for PTB. ${ }^{17} 2829$

Stressful life events and intimate partner violence during pregnancy are associated with PTB. $^{3} 30$ However, whether childhood maltreatment is associated with pregnancy complications is unclear. ${ }^{4-12}$ Much of the literature focuses on childhood sexual abuse (CSA). Fewer studies have considered physical abuse, emotional abuse or neglect, though these experiences co-occur. A handful of studies find associations of CSA or family violence with prematurity. ${ }^{4-7}$ Two suggest that alcohol and smoking among women with an abuse history explain associations of abuse with PTB. ${ }^{4}$ By contrast, other studies have not found associations between CSA and PTB $^{9} 10$ or low birth weight. ${ }^{11} 12$

Few data sets allow consideration of type of maltreatment (physical, sexual, emotional), timing of maltreatment (childhood or adolescence) and severity of maltreatment. The goal of our study is to test the hypothesis that all forms of maltreatment are associated with PTB with increased severity and earlier exposure to maltreatment having a stronger association with the outcome. The current study used data from a unique data set that allowed for an investigation of the role of type of maltreatment (physical abuse, sexual abuse and harsh parenting), timing of maltreatment ( $<10$ or 11-17) and severity of maltreatment as they relate to PTB. This data set also includes a wealth of information across a number of social, demographic and health outcomes alongside the exposure and outcome variables.

\section{METHODS}

Study population

The Nurses' Health Study II (NHS II) is a questionnaire-based longitudinal cohort begun in 1989 with 116430 registered nurses between 25 and 42 years old. Participants complete biennial 'main' questionnaires and occasional 'supplemental' questionnaires. The supplemental 2001 violence questionnaire included retrospective measures of abuse and violence histories, as well as a reproductive history, including details on up to five pregnancies lasting longer than 12 weeks. The survey was mailed to the 91297 respondents of the 2001 main questionnaire who did not request a short form questionnaire and took less than four mailings 
to complete the most recent biennial questionnaire. The response rate was $75 \%(n=65852)$. More details on the cohort can be obtained online. ${ }^{31}$

\section{Exclusions}

The sample included women completing the 2001 survey, who reported that their first pregnancy, lasting longer than 12 weeks, ended in a live birth. Those delivering before age 18, were excluded to ensure maltreatment exposure occurred prior to pregnancy $(n=867)$. The final analytic sample included 51434 participants.

\section{Exposure variables}

Harsh parenting

The short form of the Childhood Trauma Questionnaire (CTQ) measured harsh parenting, with domains of emotional abuse, neglect and/or physical abuse in childhood up to age $11 .^{32}$ Respondents answered six CTQ questions on a scale ranging from 1 (never) to 5 (all the time) about whether they were 'hit with hard objects', hit hard enough to cause 'bruises and marks', someone in their family 'yelled or screamed', said 'hurtful or insulting things', punishments seemed 'cruel', and if they felt 'important or special' (reverse coded). Item scores were summed, and ranged from 6 to 30, with high scores indicating the highest level of harsh parenting. Internal consistency was high with an $\alpha$ of 0.86 . We also created a six category variable to consider the possibility of threshold effects (ie, 6, 7-10, 11$15,16-20,21-25,26-30)$.

\section{Physical abuse}

The measure of physical abuse included items from the Revised Conflict Tactics Scale (CTS), a widely used instrument with strong validity and reliability. ${ }^{33}$ Five questions from the CTS are included in the NHS II questionnaire and asked about abuse in early childhood (0-11 years) and late childhood/adolescence (11-17 years). Respondents report frequency with which a parent, step-parent or adult guardian would 'push, grab or shove you', 'kick, bite or punch you', 'hit you with something that hurt your body', 'choke or burn you', or 'physically attack you in some other way'. Spanking for discipline was queried, but not included. Responses were combined to create a fourcategory variable of physical abuse with categories of (1) no abuse, (2) mild, (3) moderate or (4) severe physical abuse in childhood and adolescence. Mild violence included being 'hit with something' or 'kicked, bitten or punched' once, or being 'pushed, grabbed or shoved' once or a few times or more. Moderate violence included being 'physically attacked' once, or being 'hit with something' a few or more times. Severe violence included being 'kicked, bitten or punched' a few or more times, 'choked or burned' ever, or being 'physically attacked' a few or more times.

\section{Sexual abuse}

Sexual abuse refers to unwanted sexual contact between a minor (under age 18) with an older child or adult. The sexual abuse measure was derived from the survey by Finkelhor et al. ${ }^{34}$ Each item asked respondents to report sexual abuse experiences occurring either in early childhood $(<11$ years) or late childhood (11-17 years). The two items were: 'Were you ever touched in a sexual way by an adult or an older child or were you forced to touch an adult or an older child in a sexual way when you did not want to?' and 'Did an adult or older child ever force you or attempt to force you into sexual activity by threatening you, holding you down, or hurting you in some way when you did not want to?'

Respondents reported on frequency of experiences in relation to each of these items as: never, once or more than once. We created three mutually exclusive categories of sexual abuse history across childhood and adolescence: never sexually abused, sexually touched at least once (but not forced sexual activity) and forced sexual activity at least once. Women who experienced both types of sexual abuse were placed in the forced sexual activity category.

\section{Combined severe physical and sexual abuse}

This measure combines information from the physical and sexual abuse variables and includes categories of (1) no severe physical abuse or forced sexual activity, (2) severe physical abuse but no forced sexual activity, (3) forced sexual activity but no severe physical abuse, (4) those who have both severe physical abuse and forced sexual activity. Those women who experienced mild or moderate physical abuse, or women who experienced sexual touch, but not forced sexual activity were put into the no severe abuse group for this variable.

\section{Outcome variable}

Preterm birth

Gestational length of first, live birth reported in the 2001 survey was captured with a self-reported, categorical variable with categories of 12 to $<20,20$ to $<24,24$ to $<28,28$ to $<32,32$ to $<37,37$ to 42 (term) and $43+$ weeks. Live births included pregnancies lasting at least 20 weeks, with PTB defined as delivery between 20 and 37 weeks. Several studies confirm that retrospective maternal recall of gestational age at delivery is moderately to highly accurate, $\mathrm{r}=0.76-0.93 .^{35} 36$

\section{Covariates}

\section{Demographic and behavioural covariates}

Covariates were chosen based on theoretical and empirical evidence. Covariates came from the baseline survey (1989), demographic factors from the 2001 and 2005 main questionnaires and 2001 violence questionnaire, and health questions from the 2001 and 2003 surveys. Basic demographic measures included maternal race (Caucasian, African-American, other), baseline marital status (married, not married), adult income $(<\$ 30000$, \$30-\$49 999, \$50-\$74 999, \$75-\$99 999, \$100-\$149999 and $\$ 150000$ or more), child socioeconomic position (SEP) as measured by parental home ownership at respondent's birth (yes/no) and highest parental education from either parent at the time of the respondent's birth ( $<9$ years, 1-3 years of high school, 4 years of high school, 1-3 years of college, or 4 or more years of college). Maternal age was used as a continuous variable. Behavioural risk factors including quantity of cigarette use (none, $1-4,5-14$, and 15 or more cigarettes per day) and alcohol use $(0,1-4,5$ or more drinks per week) during pregnancy, physical abuse during pregnancy (yes/no), body mass index (BMI) at age 18 (occurring after abuse, but prior or concurrent with pregnancy), and age at menarche $(<11,11-14$ and $\geq 15$ years). Other potential physical and mental health sequelae such as diagnosis of heart disease, diabetes, gestational diabetes and depression were coded as dichotomous (yes/no) responses.

\section{Statistical analysis}

Analyses were conducted using SAS V.9.2 (Cary, North Carolina, USA). Descriptive statistics of independent and dependent variables and covariates were examined, followed by associations between variables using $\chi^{2}$ tests. Covariates were 


\begin{tabular}{|c|c|c|c|c|c|c|c|c|c|c|}
\hline \multirow[b]{2}{*}{ Variable } & \multirow[b]{2}{*}{$\mathrm{N}(\%)$} & \multicolumn{3}{|c|}{ Sexual abuse in childhood or adolescence* } & \multicolumn{2}{|c|}{$\begin{array}{l}\text { Childhood trauma } \\
\text { questionnaire score* }\end{array}$} & \multicolumn{4}{|c|}{ Physical abuse in childhood or adolescence* } \\
\hline & & No sexual abuse (\%) & Touch only (\%) & Forced sex (\%) & 6-20 (\%) & $21-30(\%)$ & None $(\%)$ & Mild (\%) & Moderate (\%) & Severe (\%) \\
\hline Total & $51434(100)$ & $34144(67)$ & $11403(22)$ & $5570(11)$ & 47376 (92) & $4049(8)$ & $23752(46)$ & 9669 (19) & $13615(27)$ & $4250(8)$ \\
\hline Maternal age & $27(5)$ & $27(5)$ & 27 (5) & $26(5)$ & $27(5)$ & $26(5)$ & 27 (5) & $27(5)$ & $27(5)$ & $26(5)$ \\
\hline \multicolumn{11}{|l|}{ Maternal race } \\
\hline Non-Hispanic white & 48006 (95) & 95 & 94 & 94 & 95 & 93 & 96 & 95 & 93 & 94 \\
\hline Other race & $2676(5)$ & 5 & 6 & 6 & 5 & 7 & 4 & 5 & 7 & 6 \\
\hline \multicolumn{11}{|l|}{ Highest parental education†‡ } \\
\hline Less than high school & $4845(11)$ & 9 & 13 & 14 & 10 & 15 & 9 & 10 & 12 & 15 \\
\hline 4 years high school & $19144(42)$ & 41 & 42 & 43 & 41 & 44 & 40 & 41 & 44 & 43 \\
\hline $1-3$ years college & $11316(25)$ & 25 & 24 & 24 & 25 & 23 & 25 & 25 & 24 & 24 \\
\hline $4+$ years college & $10700(23)$ & 25 & 21 & 19 & 24 & 18 & 26 & 24 & 20 & 18 \\
\hline \multicolumn{11}{|l|}{ Parents home owners $\ddagger$} \\
\hline Owned home & $24947(54)$ & 55 & 53 & 52 & 55 & 49 & 57 & 54 & 52 & 49 \\
\hline \multicolumn{11}{|l|}{ Age at menarche (years) } \\
\hline Before 11 & 3749 (7) & 7 & 8 & 10 & 7 & 9 & 7 & 7 & 7 & 9 \\
\hline $11-14$ & $43780(85)$ & 86 & 86 & 82 & 86 & 83 & 86 & 85 & 85 & 83 \\
\hline 15 or more & $3761(7)$ & 8 & 6 & 8 & 7 & 8 & 7 & 8 & 8 & 8 \\
\hline \multicolumn{11}{|l|}{ Body mass index at age 18} \\
\hline Underweight (<18.5) & 7539 (15) & 16 & 13 & 14 & 15 & 14 & 15 & 15 & 15 & 15 \\
\hline Normal weight (18.5-24.9) & 39326 (77) & 77 & 78 & 76 & 77 & 75 & 78 & 77 & 76 & 75 \\
\hline Overweight (25-29.9) & $3361(7)$ & 6 & 7 & 8 & 6 & 8 & 6 & 7 & 7 & 8 \\
\hline Obese (over 30) & $817(2)$ & 1 & 2 & 2 & 2 & 2 & 1 & 1 & 2 & 2 \\
\hline \multicolumn{11}{|l|}{ Physical abuse in pregnancy } \\
\hline No abuse & $50018(97)$ & 98 & 97 & 95 & 98 & 93 & 99 & 97 & 97 & 93 \\
\hline \multicolumn{11}{|l|}{ Weekly prenatal alcohol use } \\
\hline 0 drinks & 44070 (86) & 86 & 85 & 84 & 86 & 85 & 87 & 83 & 85 & 84 \\
\hline 1-4 drinks & 6935 (14) & 13 & 14 & 14 & 13 & 14 & 12 & 16 & 14 & 15 \\
\hline 5 or more drinks & $353(1)$ & 0.6 & 0.7 & 1 & 1 & 1 & 0.5 & 0.7 & 0.9 & 1 \\
\hline \multicolumn{11}{|l|}{ Daily prenatal cigarette use } \\
\hline None & $45086(88)$ & 89 & 87 & 83 & 88 & 83 & 90 & 86 & 87 & 82 \\
\hline Less than 1 up to 4 & $2110(4)$ & 4 & 5 & 5 & 4 & 5 & 3 & 5 & 4 & 6 \\
\hline 5-14 cigarettes & $2098(4)$ & 4 & 4 & 6 & 4 & 5 & 3 & 4 & 4 & 6 \\
\hline $15+$ cigarettes & $2080(4)$ & 3 & 5 & 7 & 4 & 7 & 3 & 5 & 5 & 7 \\
\hline \multicolumn{11}{|l|}{ Baseline marital status } \\
\hline Married & 44315 (86) & 87 & 86 & 83 & 87 & 82 & 87 & 87 & 86 & 83 \\
\hline \multicolumn{11}{|l|}{ Family income $2005 \ddagger$} \\
\hline$<50000$ & $6121(15)$ & 14 & 15 & 19 & 14 & 19 & 14 & 14 & 15 & 19 \\
\hline $50000-74000$ & $11100(26)$ & 26 & 27 & 29 & 26 & 26 & 27 & 25 & 27 & 27 \\
\hline $75000-99000$ & $9249(22)$ & 22 & 22 & 21 & 22 & 21 & 22 & 22 & 22 & 20 \\
\hline $100000-149000$ & 9999 (24) & 25 & 23 & 21 & 24 & 22 & 24 & 24 & 24 & 22 \\
\hline $150000+$ & $5552(13)$ & 14 & 12 & 10 & 13 & 12 & 13 & 15 & 13 & 12 \\
\hline
\end{tabular}


evaluated by relevance (association with the exposure or outcome), as well as evidence of confounding (using a 10\% or greater change in the effect estimate for the abuse exposure). ${ }^{37}$ Using logistic regression models, we examined associations between each type of maltreatment (physical, sexual and harsh parenting) and PTB in the first pregnancy-the pregnancy closest chronologically to the abuse exposure. Adjustment for potential confounders (model 1) were added, and then potentially mediating covariates (model 2 ). A final model was run that considered potential mental and physical health sequelae of abuse (results not shown). Timing and frequency of physical and sexual abuse on PTB by time period of early or late childhood, and frequency by which abuse occurred were then considered. Finally, the relationship between PTB and the combined severe physical and sexual abuse variable was considered. Statistical significance was set using two-tailed tests of association of 0.05 with 95\% CIs. Missing indicator analysis, where missing data are included as a dummy variable, was used as is standard with this data set. This study was approved by the Institutional Review Board of Brigham and Women's Hospital. Return of the questionnaire via US mail constituted implied consent.

\section{Sample description}

Table 1 describes characteristics of the sample. Women who reported more severe abuse tended to have lower childhood SEP, were more likely to be overweight or obese at age 18, smoke and drink during pregnancy, earn less income, experience violence during pregnancy, and not be married at baseline (table 1). Relationships between childhood abuse and covariates were similar for all types of abuse. More than half of the women (54\%) reported experiencing physical abuse exposure prior to age 18 (table 1). A third of the sample (33\%) reported experiencing sexual abuse with $11 \%$ reporting forced sexual activity. Eight per cent of the cohort experienced CTQ scores $>20$, which typically represent high levels of harsh and punitive parenting. Different forms of abuse commonly co-occurred. For example, more than a third of the women who reported physical abuse, $40 \%$, also reported sexual abuse.

\section{Childhood abuse and PTB}

Harsh parenting as measured by the CTQ was unassociated with PTB in either minimally or fully adjusted models (table 2). A small $(\sim 10 \%)$ increased odds of PTB among women with severe physical abuse in childhood was not statistically significant in either minimally or fully adjusted models. Unwanted sexual touching was not associated with likelihood of PTB, but forced sexual activity predicted a modest increase in odds of PTB (OR 1.22, CI 1.10 to 1.35; table 2). Placing physical abuse and sexual abuse in the same model, or controlling for physical and mental health variables, did not alter effect estimates (data not shown). Forced sexual activity was associated with increased odds of PTB in both childhood and adolescence (table 3). However, there was no evidence that forced sex on multiple occasions (table 4) further increased the odds of PTB. Looking at the subset of women with a history of both forced sexual activity and severe physical abuse did show a significant increased odds of PTB with an OR of 1.35 and CI from 1.13 to 1.62 (table 5). This suggests additional risk for women experiencing both forced sexual activity and severe physical abuse.

\section{DISCUSSION}

Among 52000 women, participants who experienced forced sex in childhood or adolescence had a $22 \%$ increased odds of delivering preterm in their first pregnancy lasting 12 weeks or
Table 2 ORs and 95\% Cls for combined child and adolescent abuse and odds of preterm birth with separate models being run for each type of abuse

\begin{tabular}{|c|c|c|c|}
\hline Variable & $\begin{array}{l}\text { Cases of } \\
\text { preterm/total } \\
\mathrm{N}\end{array}$ & $\begin{array}{l}\text { Model 1* } \\
\text { OR }(95 \% \mathrm{Cl})\end{array}$ & $\begin{array}{l}\text { Model } 2 \dagger \\
\text { OR }(95 \% \mathrm{Cl})\end{array}$ \\
\hline \multicolumn{4}{|c|}{ CTQ Score (0-11 years) } \\
\hline 6 & $305 / 3889$ & 1.00 & 1.00 \\
\hline $7-10$ & $1675 / 20608$ & 1.04 (0.92 to 1.18$)$ & 1.04 (0.92 to 1.19$)$ \\
\hline $11-15$ & 1269/15 933 & $1.02(0.89$ to 1.16$)$ & 1.01 (0.89 to 1.16$)$ \\
\hline $16-20$ & $515 / 6946$ & 0.94 (0.81 to 1.09$)$ & 0.93 (0.80 to 1.08 ) \\
\hline $21-25$ & 263/2966 & 1.16 (0.98 to 1.38$)$ & 1.14 (0.96 to 1.35$)$ \\
\hline $26-30$ & 83/1083 & $1.00(0.78$ to 1.29$)$ & 0.96 (0.75 to 1.24$)$ \\
\hline \multicolumn{4}{|c|}{ Combined time periods for abuse variables (0-17 years) } \\
\hline \multicolumn{4}{|l|}{ Physical abuse } \\
\hline None & 1919/23752 & 1.00 & 1.00 \\
\hline Mild & 780/9669 & $1.00(0.92$ to 1.09$)$ & 1.00 (0.92 to 1.09$)$ \\
\hline Moderate & 1033/13 615 & 0.94 (0.87 to 1.02$)$ & 0.93 (0.86 to 1.01$)$ \\
\hline Severe & $371 / 4250$ & $1.11(0.99$ to 1.25$)$ & 1.08 (0.96 to 1.22$)$ \\
\hline \multicolumn{4}{|l|}{ Sexual abuse } \\
\hline None & 2666/34 144 & 1.00 & 1.00 \\
\hline $\begin{array}{l}\text { Unwanted } \\
\text { sexual touch } \\
\text { only }\end{array}$ & $908 / 11403$ & $1.03(0.95$ to 1.11$)$ & 1.03 (0.95 to 1.11$)$ \\
\hline $\begin{array}{l}\text { Forced sexual } \\
\text { activity }\end{array}$ & $518 / 5570$ & 1.24 (1.13 to 1.37$)$ & 1.22 (1.10 to 1.35$)$ \\
\hline
\end{tabular}

longer. However, childhood physical abuse, sexual touch and harsh parenting (as measured by the CTQ score) were not associated with risk of PTB. The experience of forced sexual activity may have unique adverse outcomes not present with other forms of abuse (including sexual touching), despite abuse types co-occurring.

This study contributes to the literature by providing evidence that forced sexual activity in childhood is associated with increased odds of PTB. These findings are congruent with research that suggests CSA increases odds of PTB. ${ }^{4-7} 38$ However, it goes beyond prior research, when we compare the effects of different forms of maltreatment, and assess timing and severity of abuse, which did not appear to influence results.

There are a number of plausible mechanisms to explain a relationship between CSA and PTB including: alterations in neuroendocrine and stress response systems ${ }^{39}$; maladaptive health behaviours, such as drug and alcohol use ${ }^{4} 7$; physical damage from abuse, such as sexually transmitted infections (STIs) ${ }^{21}$; or impaired health and chronic diseases, such as obesity and diabetes, putting women at risk of medically indicated PTB. ${ }^{17} \begin{array}{llll}24 & 28 & 28 & \text { Previous research suggests alcohol use during }\end{array}$ pregnancy may mediate the association of CSA with PTB. ${ }^{4}$ However, maternal cigarette and alcohol use did not appear to attenuate the relationship between forced sexual activity and PTB in this analysis.

CSA may also activate and alter biological responses to stress causing hyperactivation of the neuroendocrine system and release of corticotrophin releasing hormone, leading to PTB. ${ }^{39}$ However, stress reactivity as a mechanism would only be consistent with our data if specific to forced sexual activity. Perhaps stress response alterations are more likely to occur among those 
Table 3 ORs and 95\% Cls for child and adolescent abuse with preterm birth with separate models being run for each type of abuse

\begin{tabular}{|c|c|c|c|}
\hline Variable & $\begin{array}{l}\text { Cases of } \\
\text { preterm/total } \\
\mathrm{N}\end{array}$ & $\begin{array}{l}\text { Model 1* OR } \\
(95 \% \mathrm{Cl})\end{array}$ & $\begin{array}{l}\text { Model 2+ OR } \\
(95 \% \mathrm{Cl})\end{array}$ \\
\hline \multicolumn{4}{|c|}{ Childhood (0-10 years) } \\
\hline \multicolumn{4}{|c|}{ Physical abuse } \\
\hline None & 2097/26 067 & 1.00 & 1.00 \\
\hline Mild & $682 / 8478$ & $1.00(0.92$ to 1.10$)$ & $1.00(0.92$ to 1.10$)$ \\
\hline Moderate & $1022 / 13349$ & 0.95 (0.88 to 1.03$)$ & 0.95 (0.88 to 1.02$)$ \\
\hline Severe & $303 / 3406$ & 1.14 (1.00 to 1.29$)$ & $1.11(0.97$ to 1.26$)$ \\
\hline \multicolumn{4}{|l|}{ Sexual abuse } \\
\hline None & $3196 / 40615$ & 1.00 & 1.00 \\
\hline Touched & $626 / 7594$ & $1.06(0.96$ to 1.15$)$ & 1.05 (0.96 to 1.15$)$ \\
\hline Forced sex & $274 / 2985$ & 1.22 (1.07 to 1.38$)$ & $1.19(1.04$ to 1.36$)$ \\
\hline \multicolumn{4}{|c|}{ Adolescence (11-17 years) } \\
\hline \multicolumn{4}{|l|}{ Physical abuse } \\
\hline None & 2797/34 631 & 1.00 & 1.00 \\
\hline Mild & $600 / 7594$ & $0.98(0.90$ to 1.08$)$ & 0.98 (0.89 to 1.07$)$ \\
\hline Moderate & $425 / 5858$ & $0.90(0.81$ to 1.00$)$ & 0.89 (0.80 to 0.99$)$ \\
\hline Severe & $282 / 3217$ & 1.12 (0.98 to 1.27$)$ & 1.09 (0.95 to 1.24$)$ \\
\hline \multicolumn{4}{|l|}{ Sexual abuse } \\
\hline None & $3220 / 40440$ & 1.00 & 1.00 \\
\hline $\begin{array}{l}\text { Unwanted } \\
\text { sexual touch } \\
\text { only }\end{array}$ & $517 / 6831$ & 0.95 (0.87 to 1.05$)$ & 0.95 (0.87 to 1.05$)$ \\
\hline $\begin{array}{l}\text { Forced sexual } \\
\text { activity }\end{array}$ & $362 / 3944$ & 1.20 (1.07 to 1.35$)$ & 1.18 (1.05 to 1.32$)$ \\
\hline
\end{tabular}

${ }^{*}$ Adjusted for maternal age, childhood socioeconomic position and maternal race. tAdjusted for maternal age, childhood socioeconomic position, and maternal race, prenatal alcohol use, prenatal cigarette use, age at menarche, marital status at baseline, reported income 2001, body mass index at 18 , and physical abuse in pregnancy.

who experienced forced sexual activity. Coping behaviours may mitigate effects of other forms of abuse, rendering their associations with PTB less consistent, which are less effective for forced sexual activity, especially when compounded by exposure to severe physical abuse.

Sexually abused children are also at risk for STIs related to their abuse, and increased sexual risk behaviours after the sexual abuse. ${ }^{20}{ }^{21}$ However, STIs have been found to be related to multiple forms of child maltreatment, not only CSA. ${ }^{20}$ Unfortunately, we lacked data on infection or inflammation during pregnancy, as well as sexual history, so this hypothesis could not be explored further.

Several limitations of this study require consideration. Although the NHS II cohort is prospective, this analysis was based on retrospective abuse and pregnancy history collected on the same questionnaire, risking recall bias. If women with PTB report more negative past experiences because of reporting their pregnancy history, this could bias the results in support of our hypothesis. However, such a bias would also presumably produce associations of PTB with physical abuse and harsh parenting.

As with most epidemiological studies of childhood abuse, we relied on self-report measures. The survey instruments were from well-established surveys focusing on specific acts of violence rather than more subjective terms such as 'abuse' or 'rape'. ${ }^{33-35}$ Alternatively, relying on data of 'reported' abuse cases would be limiting as most abuse is never reported. The rates of abuse in our sample are slightly higher than those in the
Table 4 ORs and $95 \% \mathrm{Cls}$ for the association of child and adolescent sexual abuse with preterm birth by the severity, timing and frequency of sexual abuse

\begin{tabular}{|c|c|c|c|}
\hline Variable & $\begin{array}{l}\text { Cases of } \\
\text { preterm/ } \\
\text { total } \mathrm{N}\end{array}$ & $\begin{array}{l}\text { Model 1* OR } \\
(95 \% \mathrm{Cl})\end{array}$ & $\begin{array}{l}\text { Model } 2+\text { OR } \\
(95 \% \mathrm{Cl})\end{array}$ \\
\hline \multicolumn{4}{|c|}{ Childhood sexual abuse: timing and severity } \\
\hline None & $\begin{array}{l}2666 / \\
34144\end{array}$ & 1.00 & 1.00 \\
\hline $\begin{array}{l}\text { Touched only (child } \\
\text { only) }\end{array}$ & $428 / 4982$ & $1.11(1.00$ to 1.24$)$ & 1.11 (1.00 to 1.23 ) \\
\hline $\begin{array}{l}\text { Touched only } \\
\text { (adolescent only) }\end{array}$ & $344 / 4471$ & 0.99 (0.88 to 1.12$)$ & 1.00 (0.89 to 1.12$)$ \\
\hline $\begin{array}{l}\text { Touched only (both } \\
\text { periods) }\end{array}$ & $141 / 2020$ & $0.89(0.75$ to 1.07$)$ & 0.89 (0.74 to 1.06$)$ \\
\hline $\begin{array}{l}\text { Forced sexual activity } \\
\text { (child only) }\end{array}$ & $157 / 1651$ & $1.27(1.07$ to 1.50$)$ & 1.25 (1.05 to 1.48$)$ \\
\hline $\begin{array}{l}\text { Forced sexual activity } \\
\text { (adolescent only) }\end{array}$ & $245 / 2613$ & 1.25 (1.09 to 1.44$)$ & 1.23 (1.08 to 1.42$)$ \\
\hline $\begin{array}{l}\text { Forced sexual activity } \\
\text { (both periods) }\end{array}$ & $117 / 1335$ & $1.18(0.97$ to 1.43$)$ & $1.14(0.94$ to 1.39$)$ \\
\hline \multicolumn{4}{|c|}{ Forced sexual activity: frequency } \\
\hline None & $\begin{array}{l}3580 / \\
45629\end{array}$ & 1.00 & 1.00 \\
\hline $\begin{array}{l}\text { Forced sexual activity } \\
\text { (once) }\end{array}$ & $271 / 2932$ & $1.22(1.07$ to 1.39$)$ & 1.20 (1.06 to 1.37$)$ \\
\hline $\begin{array}{l}\text { Forced sexual activity } \\
\text { (more than once) }\end{array}$ & $248 / 2667$ & 1.25 (1.09 to 1.43$)$ & 1.22 (1.06 to 1.39$)$ \\
\hline
\end{tabular}

${ }^{*}$ Adjusted for maternal age, childhood socioeconomic position and maternal race. †Adjusted for maternal age, childhood socioeconomic position, and maternal race prenatal alcohol use, prenatal cigarette use, age at menarche, marital status at baseline, reported income 2001, body mass index at 18, and physical abuse in pregnancy.

more representative sample of the National Violence Against Women Survey (40\% experienced physical abuse compared with $54 \%$ in this study and 9\% experienced rape compared with $11 \%$ with forced sexual activity in this study). ${ }^{40}$

The self-reported pregnancy outcome raises the possibility of misclassification bias. However, if the bias were non-differential, or random, the impact would bias to the null. Use of women's self-report of PTB has good accuracy, which decreases this concern. $^{36} 37$ The prevalence of PTB in this sample $(8 \%)$ is appropriate for a largely white, employed sample of singleton

Table 5 ORs and 95\% Cls for severe physical abuse and forced sexual activity during childhood or adolescence and preterm birth

\begin{tabular}{llll}
\hline Variables & $\begin{array}{l}\text { Cases of } \\
\text { preterm/ } \\
\text { total N }\end{array}$ & $\begin{array}{l}\text { Model 1* OR } \\
(95 \% \mathrm{Cl})\end{array}$ & $\begin{array}{l}\text { Model 2+ OR } \\
(95 \% \mathrm{Cl})\end{array}$ \\
\hline $\begin{array}{l}\text { Combined abuse } \\
\text { No severe abuse }\end{array}$ & $\begin{array}{l}3343 / \\
42640\end{array}$ & 1.00 & 1.00 \\
$\begin{array}{l}\text { Severe physical only } \\
\text { Forced sex only }\end{array}$ & $\begin{array}{l}232 / 2897 \\
\text { Experienced both } \\
\text { severe abuse types }\end{array}$ & $1.03(0.90$ to 1.19) & $1.02(0.88$ to 1.17) \\
\hline
\end{tabular}

*Adjusted for maternal age, childhood socioeconomic position and maternal race. †Adjusted for maternal age, childhood socioeconomic position, and maternal race, prenatal alcohol use, prenatal cigarette use, age at menarche, marital status at baseline, reported income 2001, body mass index at 18 , and physical abuse in pregnancy. 
pregnancies. ${ }^{1}$ Additionally, a sample of nurses is likely to have equal or better recall of gestational age than the community sample from the validity studies. Another concern is that spontaneous preterm labour, preterm premature rupture of membranes, and inductions for medical reasons or patient preferences were combined. This heterogeneity could attenuate associations of abuse with certain subtypes of PTB, as etiological underpinnings between indicated and spontaneous PTBs may differ. Using a data set of health professionals may mean that respondents have higher resiliency than a general population sample. However, even in this potentially resilient sample, an association was found. In addition, other important risk factors, such as preeclampsia or somatic risk factors, were not available. More information on these factors might have contributed to elucidating the mechanisms underlying the association found.

This study also has a number of unique strengths. The large sample size ensured excellent statistical power to detect even relatively small associations of PTB with child abuse history. Another strength was the inclusion of various types of maltreatment, not only CSA. Additionally, the survey includes information about frequency and timing of maltreatment, which adds insight into etiological windows of vulnerability and impacts of abuse.

The specificity of the association between forced sexual activity and PTB may suggest a discrete biological or psychological mechanism through which early forced sexual activity influences pregnancy outcomes. Future studies with detail on physical and psychological sequelae of childhood maltreatment may clarify mechanisms between CSA and PTB. Providing better strategies for the treatment of girls with a history of forced sexual activity to improve future reproductive health.

\section{What is already known on this subject}

- There is strong evidence that adverse childhood experiences are correlated with a host of negative health sequelae in adulthood.

- What is less clear is whether certain adverse events, such as childhood maltreatment, may have an independent association with health outcomes, including reproductive outcomes.

- Despite a number of negative risk factors being more common in survivors of abuse, the link between childhood abuse and adulthood reproductive health is mixed in the literature.

\section{What this study adds}

- This study was able to utilise rich level of detail on childhood abuse that includes the type, timing and severity of abuse experienced during childhood and preterm birth in adulthood.

- This study found that most forms of abuse were not associated with the outcome of preterm birth in this cohort.

- However, those who experienced forced sexual activity in childhood did have a small increased odds of preterm birth.

Acknowledgements Programming support provided by Eileen Hibert and Hee-Jin Jun.
Contributors SCS wrote the statistical analysis plan, cleaned and analysed the data, and drafted and revised the paper. She is the guarantor. JWR-E provided guidance on the data, contributed to the design of the analysis, provided interpretation of data and revised the paper. LDK contributed to the design of the analysis, interpretation of the data and revised the paper. KK provided guidance on the conception of the work, interpretation of the data and revised the paper for content. All members provided final approval of the version to be published.

Funding Center for Disease Control, Ruth L Kirschstein National Research Service Award (F31). National Institute of Health, UM1 cooperative agreement for cohort infrastructure (UM1 CA176726).

Competing interests None declared.

Provenance and peer review Not commissioned; externally peer reviewed.

Data sharing statement The Nurses' Health Studies (NHS and NHS II) have a proud history of successful collaborations with investigators external to the Brigham and Women's Hospital and Harvard School of Public Health community. For more information visit: http://www.channing.harvard.edu/nhs/?page_id=471; if you have questions after reading these guidelines, please send an email to: nhspermission@channing.harvard.edu.

\section{REFERENCES}

1 Goldenberg RL, Culhane JF, lams JD, et al. Epidemiology and causes of preterm birth. Lancet 2008;371:75-84.

2 Rich-Edwards JW, Grizzard TA. Psychosocial stress and neuroendocrine mechanisms in preterm delivery. Am J Obstet Gynecol 2005;192(5 Suppl):S30.

3 Shah PS, Shah J. Maternal exposure to domestic violence and pregnancy and birth outcomes: a systematic review and meta-analyses. J Womens Health (Larchmt) 2010;19:2017-31

4 Noll JG, Schulkin J, Trickett PK, et al. Differential pathways to preterm delivery for sexually abused and comparison women. J Pediatr Psychol 2007;32:1238-48.

5 Leeners B, Stiller R, Block E, et al. Pregnancy complications in women with childhood sexual abuse experiences. J Psychosom Res 2010;69:503-10.

6 Stevens-Simon C, McAnarney ER. Childhood victimization: relationship to adolescent pregnancy outcome. Child Abuse Negl 1994;18:569-75.

7 Harville EW, Boynton-Jarrett R, Power C, et al. Childhood hardship, maternal smoking, and birth outcomes: a prospective cohort study. Arch Pediatr Adolesc Med 2010;164:533-9.

8 van der Hulst LA, Bonsel GJ, Eskes M, et al. Bad experience, good birthing: Dutch low-risk pregnant women with a history of sexual abuse. J Psychosom Obstet Gynaecol 2006;27:59-66.

9 Grimstad H, Schei B. Pregnancy and delivery for women with a history of child sexual abuse. Child Abuse Negl 1999;23:81-90.

10 Heimstad R, Dahloe R, Laache I, et al. Fear of childbirth and history of abuse: implications for pregnancy and delivery. Acta Obstet Gynecol Scand 2006;85:435-40.

11 Grimstad H, Backe B, Jacobsen $G$, et al. Abuse history and health risk behaviors in pregnancy. Acta Obstet Gynecol Scand 1998;77:893-7.

12 Jacobs JL. Child sexual abuse victimization and later sequelae during pregnancy and childbirth. J Child Sex Abus 1992;1:103-12.

13 Finkelhor $\mathrm{D}$, Ormrod $\mathrm{R}$, Turner $\mathrm{H}$, et al. The victimization of children and youth: a comprehensive, national survey. Child Maltreat 2005;10:5-25.

14 Kendler KS, Bulik CM, Silberg J, et al. Childhood sexual abuse and adult psychiatric and substance use disorders in women: an epidemiological and case control analysis. Arch Gen Psychiatry 2000;57:953-3.

15 Klanecky AK, Harrington J, McChargue DE. Child sexual abuse, dissociation, and alcohol: implications of chemical dissociation via blackouts among college women. Am J Drug Alcohol Abuse 2008;34:277-84.

16 McFarlane J, Parker B, Soeken K. Physical abuse, smoking, and substance use during pregnancy: prevalence, interrelationships, and effects on birth weight. J Obstet Gynecol Neonatal Nurs 1996;25:313-20.

17 Noll JG, Zeller MH, Trickett PK, et al. Obesity risk for female victims of childhood sexual abuse: a prospective study. Pediatrics 2007;120:e61-7.

18 Fergusson DM, Boden JM, Horwood LJ. Exposure to childhood sexual and physical abuse and adjustment in early adulthood. Child Abuse Negl 2008;32:607-19.

19 Krabbendam L. Childhood psychological trauma and psychosis. Psychol Med 2008;38:1405-8

20 Petrak J, Byrne A, Baker M. The association between abuse in childhood and STD/ HIV risk behaviours in female genitourinary (GU) clinic attendees. Sex Transm Infect 2000;76:457-61.

21 Felitti VJ, Anda RF, Nordenberg D, et al. Relationship of childhood abuse and household dysfunction to many of the leading causes of death in adults. The Adverse Childhood Experiences (ACE) Study. Am J Prev Med 1998;14:245-58.

22 Campbell R, Greeson MR, Bybee D, et al. The co-occurrence of childhood sexual abuse, adult sexual assault, intimate partner violence, and sexual harassment: a mediational model of posttraumatic stress disorder and physical health outcomes. J Consult Clin Psychol 2008;76:194-207. 
23 Desai S, Arias I, Thompson MP, et al. Childhood victimization and subsequent adult revictimization assessed in a nationally representative sample of women and men. Violence Vict 2002;17:639-53.

24 Roy A, Janal MN, Roy M. Childhood trauma and prevalence of cardiovascular disease in patients with type 1 diabetes. Psychosom Med 2010;72:833-8.

25 Wegman $\mathrm{HL}$, Stetler C. A meta-analytic review of the effects of childhood abuse on medical outcomes in adulthood. Psychosom Med 2009;71:805-12.

26 Irish L, Kobayashi I, Delahanty DL. Long-term physical health consequences of childhood sexual abuse: a meta-analytic review. J Pediatr Psychol 2010;35:450-61.

27 Rich-Edwards JW, Spiegelman D, Lividoti Hibert EN, et al. Abuse in childhood and adolescence as a predictor of type 2 diabetes in adult women. Am J Prev Med 2010;39:529-36.

28 Riley EH, Wright RJ, Jun HJ, et al. Hypertension in adult survivors of child abuse: observations from the Nurses' Health Study II. J Epidemiol Community Health 2010;64:413-8.

29 Yogev Y, Visser GH. Obesity, gestational diabetes and pregnancy outcome. Semin Fetal Neonatal Med 2009;14:77-84.

30 Dole N, Savitz DA, Hertz-Picciotto I, et al. Maternal stress and preterm birth. Am J Epidemiol 2003;157:14-24.

31 Nurses' Health Study. http://www.channing.harvard.edu/nhs/index.php/history (accessed 14 Dec 2010).
32 Bernstein DP, Stein JA, Newcomb MD, et al. Development and validation of a brief screening version of the Childhood Trauma Questionnaire. Child Abuse Neglect 2003;27:169-90.

33 Straus M, Hamby S, Boney-McCoy S, et al. The revised Conflict Tactics Scales (CTS2): development and preliminary psychometric data. J Fam Issues 1996;17:283-316.

34 Finkelhor D, Moore D, Hamby SL, et al. Sexually abused children in a national survey of parents: methodological issues. Child Abuse Negl 1997;21:1-9.

35 Sou SC, Chen WJ, Hsieh WS, et al. Severe obstetric complications and birth characteristics in preterm or term delivery were accurately recalled by mothers. J Clin Epidemiol 2006;59:429-35.

36 Adegboye AR, Heitmann B. Accuracy and correlates of maternal recall of birthweight and gestational age. BJOG 2008;115:886-93.

37 Weng HY, Hsueh YH, Messam LLM, et al. Methods of covariate selection: directed acyclic graphs and the change-in-estimate procedure. Am J Epidemiol 2009;169:1182-90.

38 Roberts AL, Lyall K, Rich-Edwards JW, et al. Association of maternal exposure to childhood abuse with elevated risk of autism in offspring. JAMA Psychiatry 2013;70:508-15.

39 Horan DL, Hill LD, Schulkin J. Childhood sexual abuse and preterm labor in adulthood: an endocrinological hypothesis. Womens Health Issues 2000;10:27-33.

40 Tjaden P, Thoennes N. Full report of the prevalence, incidence, and consequences of Violence Against Women. National Criminal Justice Reference Service, 2000. 